\title{
Universities and smart cities : the challenges to high quality
}

\author{
Anttila, Juhani
}

2018-06-17

Anttila , J \& Jussila , K 2018 , ' Universities and smart cities : the challenges to high quality ' , Total Quality Management \& Business Excellence (Print Edition), vol. 29 , no. 9-10 , pp. 1058-1073 . https://doi.org/10.1080/14783363.2018.1486552

http://hdl.handle.net/10138/308418

https://doi.org/10.1080/14783363.2018.1486552

unspecified

acceptedVersion

Downloaded from Helda, University of Helsinki institutional repository.

This is an electronic reprint of the original article.

This reprint may differ from the original in pagination and typographic detail.

Please cite the original version. 


\title{
Universities and smart cities: The challenges to high quality
}

\author{
Juhani Anttila, Academician, M.Sc. (Electrical Engineering) \\ International Academy for Quality (IAQ) \\ E-mail: juhani.anttila@telecon.fi,www.QualityIntegration.biz \\ Kari Jussila, M.Sc. (Physical Electronics), M.Sc. (Economics) \\ University of Helsinki \\ E-mail:kari.jussila@helsinki.fi
}

\begin{abstract}
The universities have a diverse influence on the development of the society. Today this also includes countless smart city and community initiatives all over the world. These cases bring together city planning, industry, universities and citizens to improve the urban life of individuals and organizations with the integrated use of versatile information, digital and communication technologies. The purpose of this article is to consider quality management in the universities in a professional and creative way, which comprehensively covers the universities' activities of education, research and social collaboration, and which can ensure the universities' successful partnership in the smart city projects.

This article describes the key aspects related to the smart city phenomenon and development, and in this context the challenges to expanding and reinforcing the universities' quality management practices to meet the increased requirements of the collaboration with the other organizations for the quality of society through the disrupted innovations. The article brings up related conceptual bases, practical solutions and examples.
\end{abstract}

Smart cities are also manifestations of the $4^{\text {th }}$ industrial revolution and industry 4.0, which emerging phenomena imply innovations, better planning, a more participatory approach towards higher energy efficiency, better transport solutions, and intelligent use of information and communication technologies. The required collaboration with the many different involved societal parties sets requirements for quality in the universities' main activity sectors. In practice, this is ensured through organizational learning towards excellence in the overall performance of the university that implies professional quality management principles, innovations in processes and practices aligned with the other organizations of the society.

This article is based on the authors' long-term general research and practice of the business integrated quality management, and education and industry collaboration at different universities. Some parts of the material have been presented at different seminars and conferences, for instance in Chelyabinsk/Russia, Kenitra/Morocco and Kremenets/Ukraina.

Key words: higher education, university, smart city, digitalization, quality, excellence, quality management, organizational learning 


\section{Introduction: Universities in the smart urban quality development}

This article deals with the arguments and creative means for striving for high quality in the universities. In general, the importance of high quality is emphasized (ESG, 2015) in the higher education, and especially this is justified as a prerequisite for the universities' successful contributions to the development of the smart cities or communities.

Almost one thousand ranked universities (Times Higher Education, 2017) exist in different cities all over the world; the bigger cities typically have several or many universities. Many different academic university rankings are directed to emphasize the academic achievements but do not follow the traditional recognized quality concepts or principles. Hence, the universities have much to learn and develop regarding the professional quality practices. Particularly this can happen in collaboration with the other organizations, which they also are serving in the society.

Universities are essentially urban institutions. Modern universities were born and developed from the year of 859 (Arbaoui, L., 2012) onwards in the cities and on their impact, and in turn, they have influenced on the development of the cities and the whole societies. Universities play a significant role in supporting regional social cohesion, economic growth and future competitiveness (ESG, 2015). As a significant example, Humboldt University in Berlin Germany provided the model of the University of Civilization, the ideal that the science provides the basis for civilization ('Bildung durch Wissenschaft') (Hautamäki, A., 2016). This means that the University's societal responsibility arises when its research and teaching address challenges of the society, which have an important impact on people's lives and wellbeing, and whose solution requires interdisciplinary and broad interaction with the various stakeholders. In Astana, Kazakhstan, the University of Civilization especially aims at promoting the inter-ethnic harmony (Appelbaum, A., 2005). On the other hand, smart city was a key theme of the Expo2017 in Astana.

Given the desire to become increasingly knowledge-based, as is the situation regarding the smart city development, the higher education is essential to the socioeconomic and cultural development. Many university-units or their researchers have been involved and collaborated with other organizations in the smart city development projects, which have been carried out in various countries since 2011.

Smart cities aim at innovatively fulfilling the operating and living needs and expectations of the people and organizations with the smart urban infrastructure and services. Smart cities are intentionally greener, safer, faster and friendlier than the traditional ones. Hence, ultimately the smart cities also strive for the sustainable development (United Nations, General Assembly, 2015) and the quality of society.

Quality of society is a challenge to the smart city development, because in the societal context, quality is not accustomed to be dealt with in the comprehensive and systematic way by using a professional quality approach. We define the high-quality society as a good, well-functioning, well-developing, or excellent society for all the interested parties involved. Quality of society is based on the quality of the organizations in the society, including university institutions, and the results from their achievements and collaborative learning. Hence, the quality of the smart cities evolves by diffusing. In this article, the focus is on the quality of the universities and particularly in the context of their smart city involvement. Many organizations involving with the smart city development or operation are small organizations (SMEs) or startups. However, no established quality methodologies are available for those organizations yet. 
Traditionally universities have three merged activity dimensions: (a) The highest level of education, (b) academic research and dissemination of the research results, and (c) partnership and collaboration with the surrounding society including education, training, research and development projects with public and private organizations. Especially innovations play the significant role in this context (KPMG, 2017), and quality and innovation are closely related partnering disciplines. Contribution to the smart city development is a serious challenge to the universities, and in this context all the activity dimensions of the university should be considered together, because they all are organically involved in the smart city development. Fundamentally, universities are intelligent, i.e. cognitive thinking, centers, and hence for instance, according to the Rector of Tallinn University, Estonia, 'to contribute more to the society, we have set the goal of becoming the promoter of intelligent lifestyle in Estonia. The term Intelligent Lifestyle stands for making research-based decisions to improve the society in general and well-being of its citizens.' (Land, T., 2016). This is the unique strength of the universities in contributing to the development of smart cities (Deakin, M. and Al Waer, H., 2011), too.

Smart city (Mohanty, S. et al., 2016; ISO/IEC JTC 1, 2015) is not a clear concept, and it has no consistent definition among practitioners and academia. A proposed definition (Ibid.) is that smart city is a term denoting the effective integration of physical, digital and human systems in the built environment to deliver a sustainable, prosperous and inclusive future for its citizens. Hence, smart city also is a manifestation of the $4^{\text {th }}$ industrial revolution (Schwab, 2016) and industry 4.0 (European Parliament, 2016), which are currently the subject of discussions in the international fora.

The smart city phenomenon has its roots in the digitization (the conversion of analogue data into digital form) from the late $17^{\text {th }}$ century and its modern consequence digitalization (the adoption of digital technology by an organization, industry, country, etc.) from the mid-1950s (Brennen, S. and Kreis, D., 2014; Snabe, J., 2015). The smartness of the cities or society is a broad and fuzzy issue and a neverending and emergent process towards the smart, smarter and smartest societal entities. The smart city has no clear borders with the surrounding society, and it is in a continuous interaction with the actors outside the smart city area. At least implicitly, it is assumed that the smart cities will have the positive effect on the quality of the society as a whole. On the other hand, also the overall development of society influences on the smart city development.

In a practical way, a smart city is a place where traditional networks and services are made more flexible, efficient, and sustainable with the use of information, digital and telecommunication technologies, to improve the operations for the benefit of the people and organizations in the city. The different components of the smart city include smart citizen, smart governance, smart education, smart security, smart healthcare, smart building, smart infrastructure, smart transportation, smart mobility, smart energy, and smart technology (Frost \& Sullivan, 2013). Digitalization, and information and communication technology are the main enablers to transform traditional cities to smart cities. The 5G mobile networks, which are right now under development, are needed for smart transportation, and the closely related emerging technological trends, including Internet of things (IoT), Big data, Artificial intelligence (AI) and Intellectual robotics, and Blockchain, provide many unlimited opportunities for the development of the smart cities.

Because smart cities are much based on information, also information security is a core topic in the context of the smart cities (ISO/IEC JTC 1, 2015). This includes the 
knowledge area of privacy management (a human focus), information security management (an organizational focus) and cybersecurity management (a society focus), which are competences required by all partners involved with the development and operation of the smart cities. Needs for expertise in these areas are essentially important in many different organizations, including SMEs, involved with the smart city projects. Hence, this is an important education and research challenge to the universities.

Urban societies are 'scale-free networks' (Barabási, A., 2003), and hence smart city development is a diffusion process from the activities and achievements of many different independent but interacting private companies, public service organizations and institutions and influential individuals. Universities are among those actors. Smart city development is seen as a big financial effort; the estimated smart city market is likely to be worth of a cumulative $\$ 1.5$ Trillion by 2020 (Frost \& Sullivan, 2013).

A lot of smart city researches have been made, and the related reports are available, standardization activities are going on, hundreds of practical implementations are in progress all over the world, smart city conferences and Expos have taken place, and even globally the smart city award competitions have been arranged annually. Right now, the global smart city development is still in its beginning phase, and cities have started their projects within the restricted parts of the cities or with some particular smart objects and targets. In Finland we have smart city projects in six cities. In the Helsinki metropolitan area, we have smart city projects in three neighboring cities, Helsinki, Espoo and Vantaa (Forum Virium Helsinki, 2017; Lappalainen, P. et al. (Eds.), 2015), from which we have some examples in this article. In their projects, these cities have cooperation, and collaboration with the local and foreign universities. Hundreds of universities all over the world have reported their involvements and contributions in different ways in various smart city projects. Some universities have implemented smart campuses within their universities (The University of Glasgow, 2017).

\section{Excellence in the university quality performance}

Quality is imperative in all educational institutions (UNESCO, 2005) and in universities its importance is emphasized in the composite activities of education, research and societal collaboration. The university should strive for excellent performance (NIST, 2015) in a creative way by using the general professional quality management approach including recognized quality management principles and practices (ISO, 2015), which are intended for all kinds of organizations of the society. Only excellence can ensure sustained success also in the universities' smart city involvement.

Especially universities' collaboration with and services to the companies and other organizations of the society set severe quality requirements. In fact, universities should be pioneers or at least 'Primus inter pares' in their quality approach. Universities should not be isolated institutions. It is not enough that they only follow the quality references of the education sector, but also the best general professional business references applied in the other organizations of the society should be taken seriously. Quality is a global issue and it applies to all business sectors. Harmonized quality concepts, principles, and practices are foundations of the professionalism and support collaboration. Special challenges arise because the universities are multifaculty entities and quality of the university results from multidisciplinary factors. 
The term 'performance excellence' in the context of universities refers to the integrated quality approach within the management and operations of the university and its units, which results in (a) the delivery of ever-improving value to the stakeholders and contributing to organizational sustainability, (b) the improvement of overall organizational effectiveness and capabilities, and (c) the organizational and personal learning (NIST, 2014). Competitive advantages of the universities can be very versatile.

Faculties, institutes or other specialized units of the universities may be very different, and they also may be at different development stages. Hence, those units also should have different quality management approaches. When dealing with the quality management in the universities, one should consider both the university (the university corporation) as a whole and all its different operational units. In this article the general word 'organization' is used in this context to mean both the whole university and its single units.

Successful excellent operation requires surpassing challenging references and continual organizational learning. This includes:

- Exceeding the organization's own performance goals and targets.

- Succeeding in organizational performance within own academic branch in average and being among the best reference universities.

- Evidencing world class performance, including benchmarks and best practices among other organizations of the society outside the university sector.

Hence, performance excellence represents the highest level of quality in the organizations.

The overall performance of the organization is a broad concept including four main categories of performance (Ibid.):

- Stakeholder-focused performance: Organization's performance seen by its stakeholders or interested parties).

- Operational performance: Organization's internal performance including hard process performance (for example cost efficiency, throughput or lead time) and soft performance (for instance workforce skills).

- Product performance: Characteristics of the products including goods and services (Ibid.). The products of universities are mainly services.

- Financial and market performance: Operational costs, productivity, competitiveness, and market position and share, etc. Also universities compete with other educational institutions globally.

\section{Conceptual, methodological and organizational challenges}

The educational sector is in a paradox situation with regard to quality. The absolute importance of quality is highlighted in the speeches and writings but its professional conceptualization and implementation is indeterminate or ambiguous. In the sector of education, the prevailing quality practices are fragmented and inconsistent; even top universities do not necessarily have explicit professional understanding or implementation of quality, or they follow obsolete approaches. Difficulties of the universities' quality management arise from many different reasons including:

- Basic professional concepts of quality, quality management, quality improvement and quality assurance are not well-known although they are widely used in all other business sectors globally and even are internationally standardized. 
- Quality approaches in the universities - for instance according to the Bologna process (EURASHE, 2015) - are based on old-fashioned formal quality assurance systems and external control for conformity, which easily causes confusion and leads to stagnation. Need of methodological improvement has been recognized, but the consequential development has not yielded established results (PHExcel Consortium, 2014).

- The universities' quality considerations normally focus only on the education and do not cover the areas of research and social collaboration. However, all these three areas are very closely related to each other and they should be considered as a whole. This is particularly essential in the context of smart city projects.

- Many universities have not specific quality related education programs or research activity.

- Many universities do not have well established general managerial practices and culture that support effective integration of quality into the management processes.

- How to behave in competitive situations, is not familiar to universities.

- Universities are societal institutions, and their operation and development depend on decisions of those in power in the society.

- Ontological and epistemological bases of teaching/learning/collaborating and quality are not linked with the quality realization and evaluation.

- Prevailing academic evaluation culture of student and university scoring and qualifications are not aligned with the quality related evaluations.

The basic concepts of quality, quality management, quality improvement and quality assurance (ISO, 2015a) are essential prerequisites for professional realizing and implementing quality practices in all organizations including the universities. These internationally standardized and defined concepts are beneficial also in the educational sector, but they should be understood in the university context. Benchmarking with the organizations outside the educational sector could provide new ideas for the development of the universities but is not generally practiced.

According to its definition (Ibid.), the essence of the concept of quality refers to the perception of the fulfillment of the needs and expectations and satisfaction of all stakeholders of the university. Especially both teachers and students should perceive the educational processes valuable. Hence, the key challenge for quality in the universities is to recognize the needs and expectations of students and teachers, and other stakeholders involved with the university services. Hence, the general quality definition is valid also for the university environments, but the challenge is to understand and describe its meaning in the composite situation of education, research and societal collaboration. The needs and expectations of the different stakeholders cannot be standardized, nor even easily identified. In the context of the smart cities, the concept of quality should be understood in a broad sense including sustainability and quality of society and based on the large variety of the characteristic dimensions of the smart cities, in which the human aspects have the core role. These also are the particular challenges to the universities' smart city contributions.

Quality management implies coordinated activities to direct and control the organization and its processes with regard to quality. Hence, realization of the quality originates in the organization's management processes.

Quality improvement is to increase the ability to fulfill the needs and expectations of the stakeholders and hence it is a key element of the professional quality 
management. It actually is based on individual and organizational learning and innovation in the organization.

The purpose of quality assurance is to provide the stakeholders with factual information, when the organization needs to demonstrate its ability to provide outputs that fulfill requirements and aim at enhancing stakeholder satisfaction. Also quality assurance is a part of quality management. The concept, quality assurance system, that is often used in the context of higher education is at least confusing.

\section{Universities as manageable systems for quality and excellence}

High quality does not take place accidentally, but it needs a professional approach and coherent quality realization in the management and operational processes of the university and its units. Starting point for the systematic quality development is to identify the university entity and its units as organizational systems and recognize the organizational context including external and internal issues that are relevant to the purpose and strategic direction and that affect the ability to achieve the intended results of quality (ISO, 2015b).

We have used the framework model of figure 1 for characterizing the comprehensive quality management approach in the universities covering their all organizational functions and units.

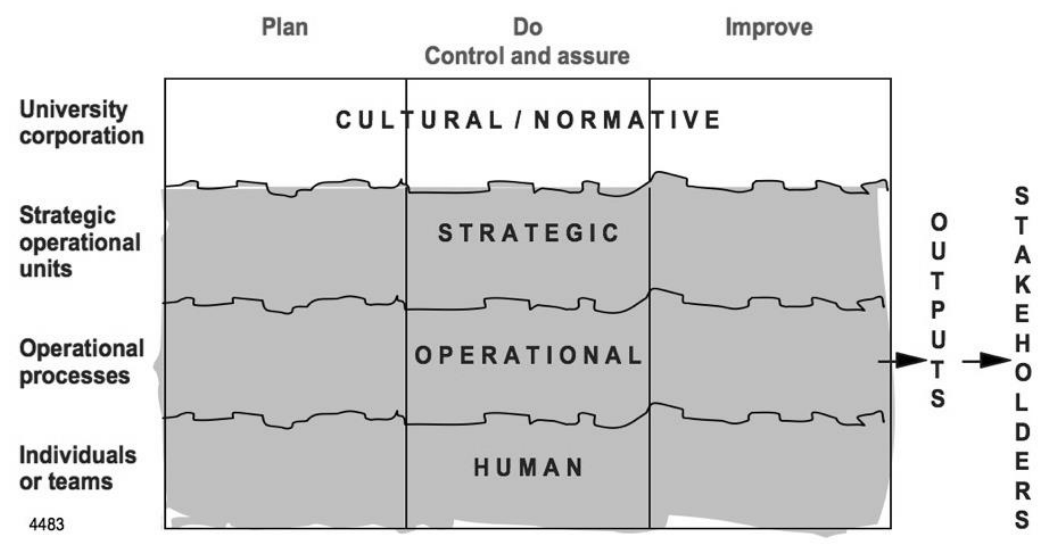

Figure 1. General management framework for the university corporation, 'universitas', consisting of different kinds of competence, responsibility and practices, and learning needed at the four organizational levels of the university. Quality related planning, doing and improving are needed at all levels.

This model covers the following four organizational levels:

- The normative and cultural level (the university corporation), where the general principles, the university-wide common insight, goals, shared tools, policies and practices concerning quality are created, including how these are to be applied in practice on the basis of the whole university's needs. Responsibility belongs to the top management, and it cannot be delegated.

- The strategic level (strategic units of the university), where decisions are made by the management of the unit, and measures undertaken concerning the entire unit's activities and especially the competitiveness of the unit in the future. The unit's operational system is composed of the interrelated operational processes. Different units may have different needs but all units operate within one organizational framework of the university. 
- The operational level (operational processes), where decisions and measures concerning daily management are made and undertaken, and products (goods and services) are realized in real time for the stakeholders' needs, just 'now and here'. Responsible person is the process owner.

- The human level (people and teams), where the personal contribution of each member of the organization's personnel (including managers) is provided in natural working environments. Responsibility is on the person him/herself.

Based on the framework of the figure 1, the different possibilities of the universities being involved with the smart city project(s) include (a) the visionary efforts of the entire university and enabling funding arrangements, (b) the strategic and operational activities of certain faculties or the university units, or (c) the involvement of the individual researchers or research teams for their own interest or merit. The last option is the most typical in Finland. The university researchers generate results, which are useful to be applied for the smart city development either directly or via different organizations, especially SMEs, that are involved with the smart city projects. The researchers themselves are not necessarily directly engaged with the smart city project.

Quality is a specialized competence that should be taken into account at all levels of the university corporation, including normative, strategic, operational and human viewpoints. Quality management measures at all these levels should be aligned. Professional and exemplary quality approach is to ensure the effective collaboration with other organizations and sustained success of the university in its activities (ISO/TC 176/SC2, 2017).

\section{Strategic intention and direction to the smart city development}

The smart city development consists of many different areas of special expertise, including citizenship, governance, education, healthcare, security, buildings, infrastructure, transportation, mobility, energy, and technology, and it requires long term efforts. Hence, the large scale smart city orientation should be based on a strategic decision of the university or its strategic units. In addition, it is necessary that the university people collaborate with other universities and different kinds of other organizations in the smart city projects.

Traditionally universities have cooperated with public organizations and private companies in research and development projects, which have aimed at beneficial results to the business of the external partners, the universities' own educational purposes and the students for their career development. Smart city projects, however, are more versatile projects requiring many different kinds of know-how, experience and cooperation with many different partners.

Strong smart city orientation in universities necessitates increasing demands for skills, competences and operations to respond in new ways towards the development of the society. Particular general viewpoints that are needed in the education, research and societal activities of the university include (1) innovative and adaptive thinking, (2) virtual collaboration and social intelligence, (3) ability to work across disciplines, (4) literacy in different types of media and (5) computational thinking and analytics (Lee, J., 2016; Schwab, K. and Samans, R., 2006). These skills are required among the university staff, but the university should also teach and promote these skills to students and partners in the smart city projects, too. The strength of the universities compared with the other smart city parties is that they are involved with multi-faculty 
education, research and industry collaboration. Hence, the university can provide many research teams of different disciplines to the smart city development.

As an example, the University of Helsinki (University of Helsinki, 2017) has to offer multidisciplinary educational, research and development, and co-operational services to the smart city projects for instance from the Faculty of

Science/Department of Computer Science (Information technology, 5G mobile communication, Internet of things, Information security, Artificial intelligence, etc.), Faculty of Biological and Environmental Sciences (Multidisciplinary urban research), Department of Geosciences and Geography (Urban geography and regional studies), Faculty of Social Sciences/ Department of Political and Economic Studies/The Consumer Society Research Centre (Societal structures and consumers) and Faculty of Arts/Department of Modern Languages (Narratives in urban planning, Digital humanities). Hence, the possibilities are multidisciplinary and unlimited.

The challenging area in the smart city development is the human focused research, although the smart city realizations have mostly emphasized technological aspects. The smart citizens (Frost \& Sullivan, 2013) have the crucial role in the smart city operations. The smart citizens possess interest in embracing smart and green solutions in their daily activities. More citizen proactivity is expected in adopting smart concepts and smart products, including lifestyle choices and individual well-being. At the University of Helsinki, these aspects are considered in the context of the digital humanities research, which also have links with the European research program SSH (Socio-economic sciences and humanities) (European Commission, 2017).

Digitalization have strong influence on people's operations, occupations and careers, employeeship, consumption patterns and social relationships.

In the context of smart citizens, the researchers and developers also should consider the 'dark side' of the digitalization, which particularly is related to the information aspects in the smart city services and their influence on the human identity and privacy, and behavior and mind development. People can be confused or misled as individuals or groups by the massive information overload, disinformation, fake news or alternative facts. Threats of the information security and privacy (ISO/IEC JTC 1, 2015) can be at risk to individuals' belongings, life and identity, because also hostile actors too exist in our societal networks. Also too strong influence of the digital environment may damage human mind, especially through addictions and the mind development of the young children (Kashmanian, K., 2000; Rowan, C. 2014).

In the field of quality, the universities could collaborate with local or international professional quality organizations and other organizations for striving for quality of society in the smart city projects. New networking and learning means based on the social media may be used in this context.

\section{Innovative organizational solutions of the universities}

Successful universities have introduced new disruptive operational practices that are not typical in the traditional university culture. Here we take as an example the Aalto University (Aalto University, 2017) in Espoo, the neighboring city of Helsinki. Aalto University has also contributed to the smart city projects in Espoo and Helsinki (Hertell, S., 2016).

In addition to the traditional educational means in the different Aalto University's schools, the university has three 'Factories' that are flexible new university units serving as joint platforms that combine the expertise of the university schools: Design Factory, Health Factory and Media Factory. These factories are designed to facilitate 
new forms of collaboration in an environment where academic teams, researchers and students work together with companies and communities. The themes of teaching and learning are important parts of the factory activities - the new knowledge produced by research is smoothly transferred to teaching. For instance, the Design Factory (Aalto Design Factory, 2017) has made a lot of cooperation with companies, and hence they have practical multidisciplinary projects, research and education in product development, marketing, international business, innovations and IPR (intellectual property rights). The results have been very successful, and the Design Factory concept has been expanded to many other universities all over the world.

The City of Espoo has co-initiated with the Aalto University the privately run Urban Mill (Urban Mill, 2016), a public-private co-working and co-creation platform for urban innovations on the Aalto University campus. Urban Mill's success is demonstrated by its 50000 users and 100 prototypes since 2013. It is a powerful example of an open innovation platform that uses a thematic approach, agile orchestration and co-creation methods to advance urban change.

Aalto University also supports students' activities for creating their entrepreneurship skills. The important example is Aaltoes (Aaltoes, 2017) (Aalto Entrepreneurship Society), which is the largest and most active student-run entrepreneurship community in Europe. Particularly interesting area, where Aaltoes is active, is the Startup activity including the concepts of Startup Sauna (Startup Sauna, 2017) and Startup Life. The success of the Startup Sauna's activities is the annual Slush event in Helsinki (Slush, 2017) that for instance in 2016 gathered together 17500 attendees, 2300 startups, 1100 investors and 600 journalists from all over the world.

These new operational modes of the university are not particularly directed to smart city projects, but many of their research and development topics are relevant from the different features of the smart cities.

Many smart city parties are small organizations or startups born in the university environments. Established quality management methodology, which can be effectively integrated with the business activities of such organizations, is not yet available, and hence, this topic is a part of our ongoing research and development. Quality management of the startups and small organizations could also be an acute education and research topic in the universities. Also the challenge is to get the university interested in the methods of the professional quality and implement them in their novel organizational solutions too, and in addition experience them as useful.

\section{University as a composite of the learning organizations for quality integration}

A university is a composite of different strategic units that can be considered as learning organizational systems. Systematic development of quality in those units means organizational learning that leads quality activities embedded into the units' managerial and operational processes (figure 1). We call this Quality Integration. Organizational learning of the universities and collaboration with the other organizations in the society also leads to the societal learning, which is essential in the smart city development.

A comprehensive model (Senge, P. et al., 1995) of the organizational learning (figure 2) can be used for developing organizational quality integration towards excellence of performance. The organizations' overall existing performance depends on how well the organization's people understand the governing principles (or guiding ideas) relevant to the particular organization, what kind of managerial tools and 
methodology they have for responding to the needs and expectations of the stakeholders, and what kind of infrastructure they have for getting the whole organization and all of its people to strive for the objectives towards the excellence goals.

In order to get better performance, the organization should establish a process to change and improve the existing guiding ideas, tools and methodologies, and the business management infrastructure (The 'Pump effect' in the figure 2). That particularly means to find new awareness, to change attitudes and beliefs, and to create new skills and competences within the organization.

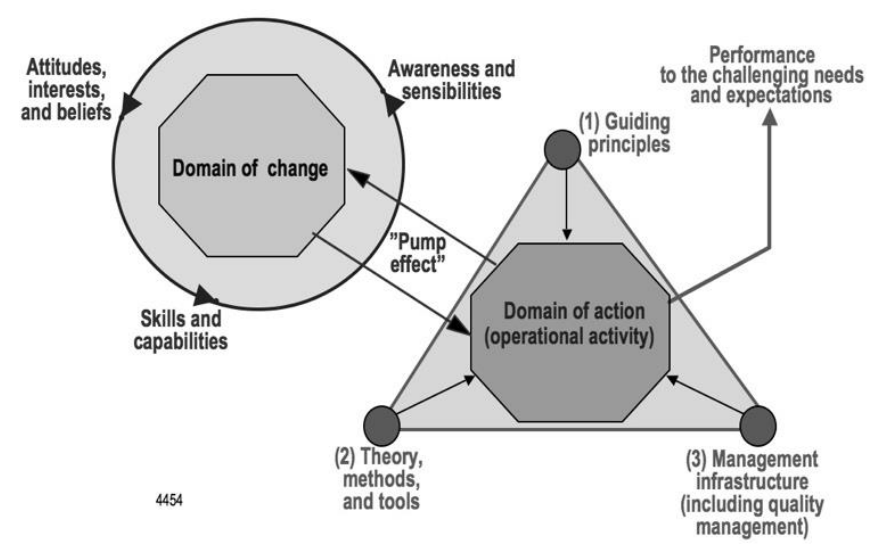

Figure 2. Foundations of the learning organization for quality integration (Ibid.)

Awareness, attitudes, skills and competences develop in the organizations through organizational learning. Incremental learning is related to certain particular skills representing different disciplines that are needed for the improved operations. Radical discontinuous change in the development is a strategic transformation process. Genuine transformation often requires a crisis. In strategic crisis there is a need for a large-scale breakthrough change in the organization's structure and processes.

Transformation means a change of form, shape or appearance, and basically it is a mental conversion (Deming, W.E., 1993). Transformations are initiated and managed from the strategic management level of the organization. Organizational transformations do not happen spontaneously or at random but by decisive actions and include consistent learning and innovations, too. Diffusion of the awareness, knowledge and skills of specialized disciplines within the organization requires personal mastery, mental models, shared vision, team learning and systems thinking (Senge, P. et al., 1995) that are important in creating new integration in an organization.

\section{Evaluation of the university quality}

Performance evaluation is a traditionally central issue of the established quality management. Many different evaluating practices have been developed for the formal educational systems and learning results, which have been used at different educational institutions nationally and internationally (UNESCO, 2005). These approaches typically focus on distinct performance aspects and are not consistently 
compatible and may be confusing in terms of the overall quality. Hence, it is essential that the evaluations have a strong theoretical and professional basis.

Quality related evaluations can apply to quality, quality management, quality improvement and quality assurance, which differ from each other in terms of purpose and methodology. The evaluations should cover the universities' all activity areas, including education, research and social collaboration and focus on enablers (processes) and results. Evaluation of the effectiveness and efficiency of the organizational systems and processes of the university is fundamentally different from the evaluation of the students', teachers' and other stakeholders' perception. Academic ranking reviews of the universities are not aligned with the professional quality evaluations. For the quality management purposes evaluations should primarily be made by the organization itself.

All evaluations should be based on sound epistemological and metrological foundations. Epistemology implies the questions what knowledge is and how it can be acquired (Allison, P. and Pomeroy, E., 2000). Knowledge is built on theory and theory is a window into the world. Interpretation of data from observations, evaluations or measurements will largely depend on the pre-knowledge of the subject matter (Deming W.E., 1993). Knowledge and experience of somebody always depends on the paradigm, which one follows intuitively or consciously. Metrology is the science of measurement and its application (OIML, 2010), and the vocabulary of metrology covers the generally accepted terms and definitions for the whole topic and for all areas of activity. Measurement means experimentally obtaining values attributed to the quantities characterizing the object. One should make clear in a practical way the meanings and roles of the concepts like fact, data, information, and knowledge, and how they are related to the measurement activity.

There are many different purposes for the evaluations, including:

- Research for getting new knowledge of the organizational performance.

- Acquisition of information for planning the university operations.

- Controlling operations and processes.

- Measurements for problem solving and performance improvement.

- Measurements for quality assurance.

The most important purposes of the evaluations relate to performance improvement and quality assurance.

Recognized evaluation related practices for educational institutions from quality point of view include (ISO/PC 288, 2016):

- Monitoring, measurement, and diagnostic analysis and evaluation

- Internal audit

- Management review

- Self-assessment

These practices are not, however, well-established in practice in the educational sector. Especially the self-assessments should be emphasized as the important part of the organization's quality management.

The main issue is to integrate the self-assessments into the management of the organization effectively and in a natural way. Some of the assessment items relate to the results and the others to enablers, i.e. the processes through which the results have been achieved. In order to achieve excellent performance, the organization cannot optimize a single area of activities and neglect the entirety, and one should recognize connections between the performance of the processes (enablers) and the results. Scoring is based on the assessment criteria (table 1) (NIST, 2014). Processes and 
results are assessed separately but the criteria emphasize the causal relations between them.

Table 1. Scoring dimensions for the self-assessment. Processes and results are assessed separately and scored from 0 to $100 \%$ according to the scoring criteria.

\begin{tabular}{|c|c|}
\hline Processes & Results \\
\hline $\begin{array}{l}\text { 1. Approach: The planned actions, } \\
\text { including process plans, measures and } \\
\text { deployment of requirements } \\
\text { 2. Deployment: Executing the planned } \\
\text { approach in practice } \\
\text { 3. Learning: Capturing new knowledge, } \\
\text { including new innovations } \\
\text { 4. Integration: Embedding the approach } \\
\text { in the organization's strategies and the } \\
\text { management of the processes and } \\
\text { activities. }\end{array}$ & $\begin{array}{l}\text { 1. Level: Levels of the achieved results } \\
\text { 2. Trends: Sustainability and the rate of } \\
\text { improvement of the performance results } \\
\text { over time } \\
\text { 3. Comparisons: Performance relative to } \\
\text { appropriate comparisons or benchmarks } \\
\text { 4. Integration: Achieving the results in a } \\
\text { balanced and comprehensive manner } \\
\text { according to the organization's strategic } \\
\text { objectives and anticipating the future } \\
\text { development. }\end{array}$ \\
\hline
\end{tabular}

As the conclusion, the key issues for the development of the strategic university units towards high quality and performance excellence is learning and integration.

\section{Reference guidance of quality management for universities}

One can find significant general ideas for quality integration from the rich professional quality literature, teachings of the recognized gurus of quality profession, and through benchmarking the practices of world class organizations. In addition, international standards are important references for quality management, too. However, these information sources are not well known among the educational organizations, including universities. In addition, these references unfortunately give a very fragmented understanding of the quality practices, and hence their consistent application can be difficult without reasonable theoretical and holistic professional quality know-how.

International ISO 9000 standards are the most well-known and widely used general business independent quality management standards. They have been the major references for the development of quality management approaches in all kinds of organizations globally during more than three decades. ISO 9000 standards also define the universal quality management principles that are the fundamental truths or propositions that serve as the foundation for a system of belief or behavior, or for a chain of reasoning for the standardized approach of the quality management. ISO 9000 basic standards series consist of three standards, ISO 9000 (ISO, 2015a), ISO 9001 (ISO, 2015b) and ISO 9004 (ISO/TC 176/SC2, 2017), considering terminology, requirements and guidance for quality management. These standards are well applicable in a creative way also in the universities when integrated within the processes in a creative way and with good professional knowledge of quality.

The education specific standard ISO 21001 (ISO/PC 288, 2016) (now at the draft stage) will challenge all educational organizations, because it requires the adoption of the general basic quality concepts and quality management structures and practices. The standard will enable educational organizations to demonstrate their ability to provide consistent education and hence to increase the credibility of the organization and enhance the satisfaction of the stakeholders of the educational organizations. 
Unfortunately, this standard focus only on the area of education but does not consider the two other areas of the university activities.

The American Baldrige Excellence Framework (Education) (NIST, 2015) is the leadership and performance management framework for the education sector that empowers the educational organization to accomplish its mission, improve results, and become more competitive. This framework model is particularly useful for selfassessments of the overall performance of the educational organizations. The framework includes:

- The core values and concepts (beliefs and behaviors found in high-performing organizations)

- The education criteria for performance excellence covering critical aspects of achieving excellence throughout the organization

- Guidelines for responding to the education criteria and evaluating and scoring processes and results

\section{Conclusions}

Quality is a generally recognized professional discipline with more than 100 years of modern successful evolution. Quality is imperative in all educational institutions for their benefits, and also the universities should follow the quality principles and practices that are applied globally in all kinds of organizations of our societies. This applies to all activity sectors of the universities including the education, research and societal collaboration. Universities also should act as advanced quality role models, and scientifically and educationally contribute to the development and dissemination of the quality philosophy and methodologies widely in the society. This however requires strive for excellence in the universities' own development of quality integration.

Smart cities aim at the effective integration of physical, digital and human systems in the built environment in order to deliver a sustainable, prosperous and inclusive future for its citizens. Smart city projects are taking place through collaboration of many public and private organizations everywhere in the world. Participation in these projects is a big challenge for the universities, where their strengths are multidisciplinary activity in education, research and societal cooperation, and the success can be ensured with the high quality and professional quality management of the universities.

\section{References}

Aalto Design Factory (2017). Educating the world's best product designers. http://designfactory.aalto.fi/.

Aalto University (2017). http://www.aalto.fi/en/.

Aaltoes (2017). https://aaltoes.com/.

Allison, P. and Pomeroy, E. (2000). How shall we 'know'? Epistemological concerns in research in experimental education. The journal of experimental education. Fall 2000, Vol. 23. http://www33.homepage.villanova.edu/edward.fierros/pdf/Allison\%20Pomeroy\%20Know.pdf.

Appelbaum, A. (2005). World-renowned architect building audacious site in Kazakhstan. http://www.eurasianet.org/departments/civilsociety/articles/eav031805.shtml.

Arbaoui, L. (2012). Al Karaouin of Fez (Morocco): The oldest university in the world, Morocco World News. https://www.moroccoworldnews.com/2012/10/59056/al-karaouin-of-fez-the-oldest-universityin-the-world/. 
Barabási, A. (2003). Linked: How everything is connected to everything else and what it means for business, science, and everyday life. Plume Books. New York, USA.

Brennen, S. and Kreis, D. (2014). Digitalization and digitization.

http://culturedigitally.org/2014/09/digitalization-and-digitization/.

Deakin, M. and Al Waer, H. (2011). From intelligent to smart cities, Intelligent Buildings International 3, pp. 133-139.

http://www.tandfonline.com/doi/pdf/10.1080/17508975.2011.586673?needAccess=true.

Deming, W.E. (1993). The new economics for industry, government, education, MIT Center for Advanced Engineering Study. Cambridge, MA, USA.

ESG (2015). Standards and guidelines for quality assurance in the European higher education area. EURASHE, Brussels, Belgium. http://www.eua.be/Libraries/quality-assurance/esg_2015.pdf?sfvrsn=0.

EURASHE (2015). Standards and guidelines for quality assurance in the European higher education area (ESG). Brussels, Belgium. https://www.eqar.eu/fileadmin/documents/bologna/ESG_2015.pdf.

European Commission (2017). Research \& innovation, social sciences and humanities. http://ec.europa.eu/research/social-sciences/index.cfm?pg=about.

European Parliament (2016). Directorate General for internal policies. Policy Department A. Economic and scientific polity. Industry 4.0.

Forum Virium Helsinki (2017). Kalasatama smart city district of Helsinki (as an example from Finland), https://fiksukalasatama.fi/en/smart-city/.

Frost \& Sullivan (2013). Strategic opportunity analysis of the global smart city market. http://www.egr.msu.edu/ aesc310-

web/resources/SmartCities/Smart\%20City\%20Market\%20Report\%202.pdf.

Hautamäki, A. (2016). Neohumboltian university - The solution for the dilemma of civilization and benefit (Uushumboldtilainen yliopisto - Ratkaisu sivistyksen ja hyödyllisyyden dilemmaan) (In Finnish). Politiikasta - Ajankohtainen ja ajaton tiedeverkkolehti 6.5.2016. https://jyx.jyu.fi/dspace/bitstream/handle/123456789/50797/hautamakipolitiikasta.pdf?sequence=1.

Hertell, S. (2016). Espoo Innovation Garden: Northern hotspot of youth, innovation and startups. http://cor.europa.eu/rie/Pages/story-9.aspx.

ISO (2015a). ISO 9000 Quality management systems - Fundamentals and vocabulary. ISO, Geneva, Switzerland.

ISO (2015b). ISO 9001 Quality management systems - Requirements. ISO, Geneva, Switzerland.

ISO/IEC JTC 1 (2015). Smart cities, ISO Geneva Switzerland.

https://www.iso.org/files/live/sites/isoorg/files/developing_standards/docs/en/smart_cities_reportjtc1.pdf.

ISO/PC 288 (2017). ISO/DIS 21001 Educational organizations management systems - Requirements with guidance for use (Draft).

ISO/TC 176/SC2 (2017). Working drafts for the standard ISO 9004:2018 (planned), Quality of an organization - Guidance to achieve sustained success. (Not published).

Kashmanian, K. (2000). The impact of computers on schools: Two authors, two perspectives. http://technologysource.org/article/impact_of_computers_on_schools/.

KPMG (2017). The changing landscape of disruptive technologies. Global technology innovation hubs. https://info.kpmg.us/content/dam/info/tech-innovation/disruptive-tech-2017-part1.pdf.

Land, T. (2016). Presentation of the Rector of Tallinn University. ARENE meeting in Tallinn in November 2016 (From T. Kekäle).

Lappalainen, P., Markkula, M. and Kune, H. (Eds.) (2015). Orchestrating regional innovation ecosystems - Espoo innovation garden.

https://urbanmillblog.files.wordpress.com/2015/04/eka_final_cover_hires.pdf.

Lee, J. (2016). 5 key skills needed in the digital economy. https://www.linkedin.com/pulse/5-keyskills-needed-digital-economy-jaclyn-lee-phd?trk=mp-reader-card. 
Mohanty, S., Choppali, U. and Kougianos, E. (2016). Everything you wanted to know about smart cities. IEEE Consumer Electronics Magazine Vol. 5, Issue 3.

http://ieeexplore.ieee.org/document/7539244/.

NIST (National Institute for Standards and Technology) (2014). Baldrige excellence framework. http://www.nist.gov/baldrige/publications/business_nonprofit_criteria.cfm.

NIST (National Institute for Standards and Technology) (2015). Baldrige excellence framework (Education). https://www.nist.gov/baldrige/publications/baldrige-excellence-framework/education.

OIML (International Organization of Legal Metrology) (2010). OIML V 2-200, International Vocabulary of Metrology - Basic and General Concepts and Associated Terms (VIM). Geneva, Switzerland. http://www.oiml.org/publications/V/V002-200-e10.pdf.

PHExcel Consortium (2014). Quality tools for professional higher education review and improvement, Eurashe, Brussels Belgium. http://files.eurashe.eu/library/qualityhe/PHExcel_Quality\%20Tools\%20for\%20PHE\%20Review\%20and\%20Improvement_2014.pdf.

Rowan, C. (2014). 10 reasons why handheld devices should be banned for children under the age of 12. http://www.huffingtonpost.com/cris-rowan/10-reasons-why-handheld-devices-should-bebanned_b_4899218.html.

Schwab (2016). The Fourth Industrial Revolution: What it means, how to respond. World Economic Forum. https://www.weforum.org/agenda/2016/01/the-fourth-industrial-revolution-what-it-means-andhow-to-respond/.

Schwab, K. and Samans, R. (2006). The future of jobs. Employment, skills and workforce strategy for the fourth industrial revolution. World Economic Forum. http://reports.weforum.org/future-of-jobs2016/preface/.

Senge, P., Roberts, C., Ross, B, and Kleiner, A. (1995). The fifth discipline fieldbook: Strategies and tools for building a learning organization. Nicholas Brealey Publishing Limited. London, UK.

Slush (2017). Not the Californian sun but honest Slush. http://www.slush.org/about/what-is-slush/.

Snabe, J. (2015). What will digitalization do to the future? https://www.weforum.org/agenda/2015/11/what-will-digitalization-do-to-the-future/.

Startup Sauna (2017). http://startupsauna.com/.

The University of Glasgow (2017). World changing campus. http://www.gla.ac.uk/about/campus/overview/smartcampus/.

Times Higher Education (2017). World university rankings 2016-2017. https://www.timeshighereducation.com/world-university-rankings/2017/worldranking\#!/page/0/length/25/sort_by/rank/sort_order/asc/cols/stats.

UNESCO (2005). Education for all, The quality imperative. http://unesdoc.unesco.org/images/0013/001373/137333e.pdf.

United Nations, General Assembly (2015). Resolution adopted by the General Assembly on 25 September 2015, Transforming our world: the 2030 Agenda for sustainable development. A/RES/70/1. http://www.un.org/ga/search/view_doc.asp?symbol=A/RES/70/1\&Lang=E.

University of Helsinki (2017). The University of Helsinki in brief. https://www.helsinki.fi/en/university/the-university-of-helsinki-in-brief.

Urban Mill (2016). Urban Mill - Building IntenCity! Co-working and co-creation platform prototype for urban innovations - Entrepreneurial thought in action! https://urbanmill.org/english/. 